Family Profile No. 04, 2018

\title{
Grandparents' Characteristics by Age
}

Author: Huijing Wu

Grandparenthood is more common among older adults (aged 65 and older) than those in midlife (aged 40-64). Using data from the 2014 Survey of Income and Program Participation (SIPP), this profile updates FP-14-13 comparing midlife grandparents to those at older ages across demographic characteristics. The SIPP is a nationally representative household-based survey and is designed to provide comprehensive family and social information on individuals and families. Because the SIPP gathers information on all individuals who lived in a surveyed household, and directly asks respondents if they are a grandparent, it is one of the few surveys that identifies non-resident grandparents. This is the fourth in our series on grandparents in the U.S.

Prevalence of Grandparenthood by Age

- About one-third of adults aged 40 to 64 were grandparents, representing about 34 million adults.

- Approximately 3 in 4 older adults (aged 65 and older) were grandparents. This represents 34 million grandparents.

\section{In 2014, 68 million adults aged 40 and over were grandparents representing just under half (46\%) of the total population in that age group.}

Race/Ethnicity of Grandparents by Age

- Midlife grandparents more often belonged to a racial/ethnic minority group than older grandparents.

- Roughly, one-third of midlife grandparents and one-fifth of older grandparents belonged to a racial/ethnic minority group.

o Comparable shares of midlife grandparents were Black or Hispanic ( $15 \%$ and $16 \%$, respectively). Only $3 \%$ of midlife grandparents were Asian.

- Similarly, a comparable share of older grandparents were Black or Hispanic ( $8 \%$ and $9 \%$, respectively). A small proportion of older grandparents were Asian (4\%).

- Whites comprise a higher proportion of older grandparents compared to midlife grandparents ( $79 \%$ and $66 \%$, respectively).
Figure 1. Grandparenthood by Age

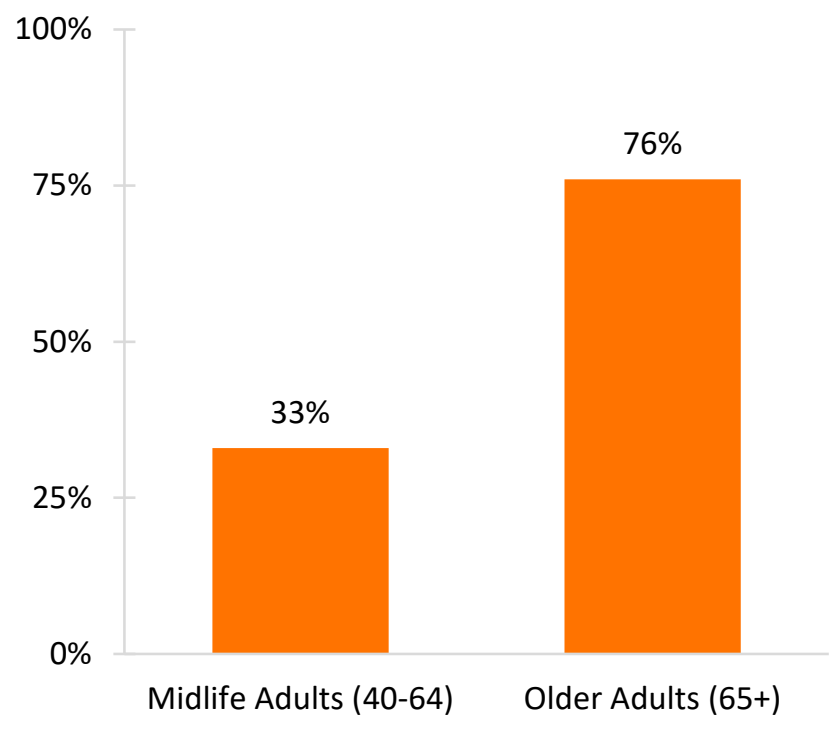

Source: NCFMR analyses of U.S. Census Bureau, Survey of Income and Program Participation, 2014

Figure 2. Race/Ethnicity of Grandparents by Age

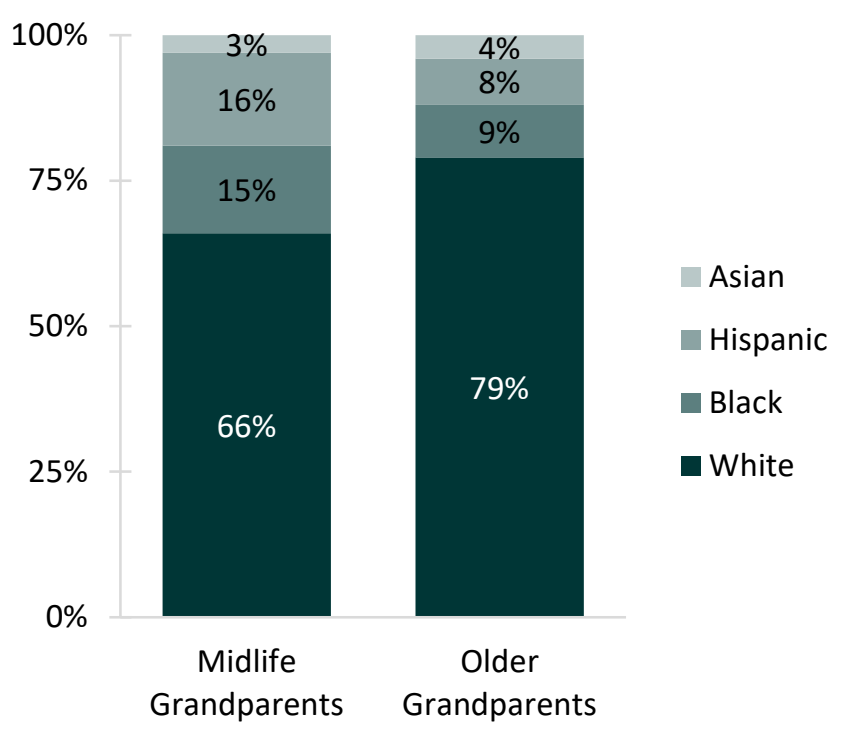

Source: NCFMR analyses of U.S. Census Bureau, Survey of Income and Program Participation, 2014 
Educational Attainment of Grandparents by Age

Figure 3. Educational Attainment of Grandparents by Age

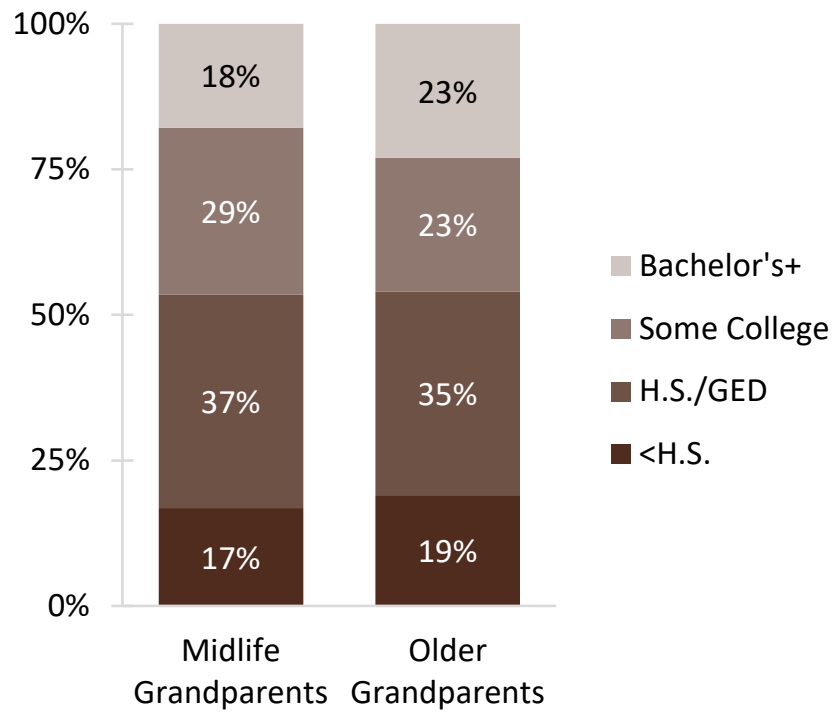

Source: NCFMR analyses of U.S. Census Bureau, Survey of Income and Program Participation, 2014

- The education differences among midlife and older grandparents were modest.

- Nearly one-quarter of older grandparents (23\%) had at least a college degree in contrast to less than one-fifth $(18 \%)$ of midlife grandparents.

- Similar shares of midlife and older grandparents had less than a high school education (17\% and $19 \%$, respectively).
Relationship Status of Grandparents by Age

Figure 4. Relationship Status of Grandparents by Age

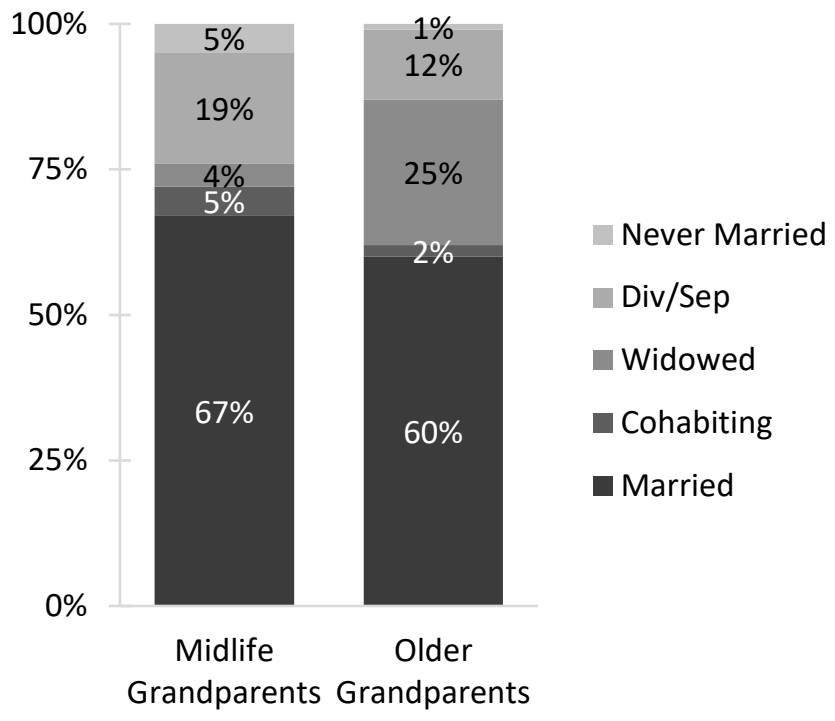

Source: NCFMR analyses of U.S. Census Bureau, Survey of Income and Program Participation, 2014

- Midlife grandparents and older grandparents differed in their relationship status.

- The majority of grandparents were married, with $67 \%$ of midlife grandparents and $60 \%$ of older grandparents.

- Midlife grandparents were more often divorced or separated (19\%) than their older counterparts (12\%).

- One-quarter of older grandparents were widowed compared to only $4 \%$ of midlife grandparents.

- Few grandparents were cohabiting or never married. Midlife grandparents were more often in a cohabiting relationship (5\% versus $2 \%$ ) or never married ( $5 \%$ versus $1 \%$ ) than older grandparents.

\section{Data Source:}

U.S. Census Bureau, Survey of Income and Program Participation, 2014 Panel, Wave 1. https://www.census.gov/programssurveys/sipp/data/2014-panel/wave-1.html

\section{References:}

Stykes, B., Manning, W. D., Brown, S. L. (2014). Grandparenthood in the U.S.: Grandparents' characteristics by life stage. Family Profiles, FP-1413. Bowling Green, OH: National Center for Family \& Marriage Research.https://www.bgsu.edu/content/dam/BGSU/college-of-arts-andsciences/NCFMR/documents/FP/FP-14-13-grandparent-lifestage.pdf

\section{Suggested Citation:}

Wu, H. (2018). Grandparents' characteristics by age. Family Profiles, FP-18-04. Bowling Green, OH: National Center for Family \& Marriage Research. https://doi.org/10.25035/ncfmr/fp-18-04.

BCSU. National Center for
B o w L I N G G R E E N S T A t E U N I v E R s I T Y
This project is supported with assistance from Bowling Green State University. From 2007 to 2013, support was also provided by the U.S. Department of Health and Human
Services, Office of the Assistant Secretary for Planning and Evaluation. The opinions and conclusions expressed herein are solely those of the author(s) and should not be construed
as representing the opinions or policy of any agency of the state or federal government.

